\title{
Análise das relações e ações conjuntas entre as empresas do APL têxtil da região metropolitana de São Paulo: contribuições para o seu crescimento
}

Analysis of conjoint relations and actions between the companies of the textile APL of the metropolitan region of São Paulo: contributions to its growth Analyse des relations et des actions conjointes entre les entreprises de l'APL
textile de la zone métropolitaine de São Paulo: contributions a leur croissance Análisis de las relaciones y acciones conjuntas entre las empresas en el APL textil de la región metropolitana de São Paulo: contribuciones para su crecimiento

\author{
Esdras da Silva Costa ${ }^{1}$ \\ Alessandra Preto Bitante ${ }^{1}$ \\ Lidiane Campos Britto ${ }^{1}$ \\ Luciane Ribeiro Dias Pinheiro ${ }^{1}$ \\ Milton Carlos Farina ${ }^{1}$
}

Recebido em 16/05/2017; revisado e aprovado em 25/07/2017; aceito em 16/08/2017

DOI: http://dx.doi.org/10.20435/inter.v0i0.1602

\begin{abstract}
Resumo: Com base na teoria dos Arranjos Produtivos Locais (APL), as empresas buscam interações, a fim de atender suas necessidades e obter ganhos futuros. O presente artigo busca caracterizar as conexões estabelecidas entre os atores inseridos no APL têxtil da região metropolitana de São Paulo por meio da Análise de Redes Sociais (ARS). Trata-se de uma pesquisa descritiva para evidenciar as conexões estabelecidas entre as empresas do APL. A análise das medidas indicaram pouca cooperação e realização de negócios entre as empresas, de forma que as vantagens de participar do APL necessitam ser mais exploradas. Há necessidade de uma reflexão mais abrangente a respeito da atuação das empresas, dos agentes externos e das potencialidades locais.
\end{abstract}

Palavras-chave: Análise de Redes Sociais; Arranjo Produtivo Local; relações e ações conjuntas; região metropolitana de São Paulo.

\begin{abstract}
Based on the theory of Local Productive Arrangements (APL), companies seek interactions in order to meet their needs and obtain future gains. This article aims to characterize the connections established between the actors included in the textile APL of the São Paulo metropolitan region through Social Network Analysis (ARS). This is a descriptive research to show the connections established between the APL companies. The analysis of the measures indicated little cooperation and business conduct between the companies, so the advantages of participating in the APL need to be further explored. There is a need for a more comprehensive reflection on the performance of companies, external agents and local potentialities.

Keywords: Social Network Analysis; Local Productive Arrangement; relations andconjoint actions; metropolitan region of São Paulo.

Resumé: Sur la base de la théorie des Arrangements Productifs Locaux (APL), les entreprises recherchent des interactions afin de répondre à leurs besoins et d'obtenir des gains futurs. Cet article vise à caractériser les liens établis entre les acteurs inclus dans l'APL textile de la zone métropolitaine de São Paulo par le biais de l'analyse des réseaux sociaux (ARS). II s'agit d'une recherche descriptive pour montrer les liens établis entre les entreprises APL. L'analyse des mesures a indiqué une faible coopération et une conduite commerciale entre les entreprises, de sorte que les avantages de participer à l'APL doivent être explorés plus avant. II faut une réflexion plus complète sur les performances des entreprises, des agents externes et des potentialités locales. Mots-clés: Analyse des Réseaux Sociaux; Arrangement Productif Local; relations et actions conjointes; zone métropolitaine de São Paulo.
\end{abstract}

Resumen: Basándose en la teoría de las Aglomeraciones Productivas Locales (APL), las compañías buscan interacciones para satisfacer sus necesidades y obtener ganancias futuras. Este artículo pretende caracterizar las conexiones establecidas entre los actores incluidos en el APL textil de la Región Metropolitana de São

\footnotetext{
${ }^{1}$ Universidade Municipal de São Caetano do Sul (USCS), São Caetano do Sul, São Paulo, Brasil.
} 
Paulo a través del Análisis de Redes Sociales (ARS). Se trata de una investigación descriptiva para mostrar las conexiones establecidas entre las empresas del APL. El análisis de las medidas indicó poca cooperación y conducta empresarial entre las empresas, por lo que las ventajas de participar en el APL necesitan ser exploradas más a fondo. Se requiere una reflexión más amplia sobre el desempeño de las empresas, agentes externos y potencialidades locales.

Palabras clave: Análisis de Redes Sociales; Aglomeración Productiva Local; relaciones y acciones conjuntas; región metropolitana de São Paulo.

\section{INTRODUÇÃO}

As mudanças ocorridas na estrutura da Região Metropolitana de São Paulo são consideradas indutoras do desenvolvimento metropolitano, e podem ser compreendidas como: surgimento de clusters produtivos e comerciais, economias de aglomeração e cidades polarizadas atribuídos aos atores locais, incertezas a respeito de um modelo competitivo desarticulado, caracterizado por um capital relacional pouco desenvolvido. Nesse contexto Micros, Pequenas e Médias Empresas (MPMEs) passaram a ter papel relevante nas regiões metropolitanas, em virtude da necessidade de organização, cooperação e aprendizagem em Arranjos Produtivos Locais (APLs) (CARDOSO; CARNEIRO; RODRIGUES, 2014).

Essa importância se dá, sobretudo, pela condição competitiva natural condicionada pelos APLs, visto que o âmbito da colaboração ultrapassa os limites organizacionais e reúne diversas iniciativas a fim de resolver problemas estratégicos e coletivos, nem sempre tão claros, e compartilhados entre os atores. Desse modo, a ação conjunta torna-se uma condição básica para habilitar as conjunturas em redes interorganizacionais à eficiência coletiva (SCHMITZ; NADVI, 1999).

Assim, os APLs representam a possibilidade de sinergia entre seus atores, além de que um APL desenvolvido proporciona vantagens locacionais quando comparado com empresas que se encontram em condições isoladas, isto é, não pertencentes a um arranjo. As empresas membros de um APL podem compartilhar riscos e ampliar as suas capacidades de flexibilidade, adaptação, estratégia, articulação política local e alavancagem, com beneficios de socialização entre as empresas envolvidas (WITTMANN; DOTTO, 2006).

O APL têxtil, foco deste estudo, foi criado em 2013 e possui, em sua configuração, 40 empresas responsáveis pela confecção de diversos modelos de figurinos, dentre eles: trajes a rigor, noivas, roupas profissionais, uniformes escolares etc. O APL também conta com a coparticipação de um grupo empresarial, como uma espécie de associação dos produtores locais, responsável por implementar ações que visam ao crescimento do setor têxtil e de confeções concentrado na Região Metropolitana. Sendo assim, o APL têxtil é constituído em sua maioria por Micro e Pequenas Empresas (MPEs), responsáveis por movimentar uma parcela da economia local e possui um contingente operacional constituído principalmente por colaboradores do gênero feminino.

Nesse contexto, a Análise de Redes Sociais (ARS) apresenta-se como uma abordagem capaz de compreender as conexões entre um conjunto de pessoas, organizações e entidades sociais, conectadas por relacionamentos, relações de trabalhos e o compartilhamento de informações (AHUJA, 2000; TOMAÉL; MARTELETO, 2006). Neste estudo científico, a abordagem de redes sociais contempla os membros de um APL e, portanto, as diversas ações colaborativas que poderão existir entre os seus atores.

O artigo traz uma breve contextualização acerca do termo Arranjo Produtivo Local (APL), descrito em uma perspectiva de Análise de Redes Sociais (ARS) para compreender suas conexões existentes, além de proporcionar novas contribuições para os estudos de Análise de Redes Sociais 
centrados sob a ótica dos APLs. Assim cabe realizar, neste estudo, de forma descritiva, a análise das relações e ações conjuntas entre os membros do APL pesquisado, compreendendo as conexões para o seu crescimento, estabelecidas entre os atores membros do APL têxtil localizado na Região Metropolitana de São Paulo.

\section{REFERENCIAL TEÓRICO}

O referencial teórico construído para a pesquisa busca fazer uma caracterização histórica da evolução dos termos: Distritos Industriais, Sistema de Produção Local e Arranjos Produtivos Locais (APLS). Foram levantadas informações a respeito da Região Metropolitana de São Paulo, com ênfase para o APL têxtil concentrado territorialmente na região, contemplando por fim um embasamento teórico da Análise de Redes Sociais (ARS).

\subsection{Análise de Redes Sociais (ARS)}

A Análise de Redes Sociais surge como uma das formas para se realizar pesquisas nas áreas de ciências sociais aplicadas, buscando compreender as relações entre seus diversos atores (FARINA, 2014). O termo "Análise de Redes Sociais" possui sua origem vinculada à expressão inglesa Social Network Analysis com suas abordagens relacionadas aos estudos de pequenos grupos na sociometria, das relações interpessoais analisadas pelos pesquisadores de Harvard, e das relações nas comunidades investigadas pelos antropólogos de Manchester (SCOTT, 2000).

O ambiente das redes sociais proporciona relações entre seus participantes por meio de estabelecimento de objetivos em comum e proximidade espacial (geográfica). A adoção de redes sociais também pode estar ligada a uma busca mobilizada de recursos, além da possibilidade de integrar novos atores, desse modo, compartilhando dos mesmos objetivos com novos entrantes na rede (SILVA et al., 2006).

Para compreender as redes sociais, é preciso estudar suas diversas possibilidades relacionais, ou seja, os relacionamentos exercidos entre os membros participantes de uma rede. Sendo assim, os estudos direcionados para a compreensão sobre redes sociais envolvem pessoas e grupos econômicos (empresas), sempre proporcionando um entendimento sobre suas ações e movimentos. São exemplos de ações e movimentos em uma rede social as trocas de informações e operações comerciais entre os membros que compõem a rede, criando laços e ligações entre os seus atores (WASSERMAN; FAUST, 1994). De acordo com Ahuja (2000), essas ligações podem ser compreendidas como ações colaborativas entre empresas, sendo as redes sociais também responsáveis por compartilhar conhecimentos e habilidades. As redes sociais funcionam como propagação de informações entre seus atores, tendo como base o know-how e atividades já exercidas por seus participantes.

Os estudos relacionados a Análises de Redes Sociais ganharam destaque com a crescente expansão dos bancos de dados, ambos relacionados ao crescimento das Tecnologias de Informação e Comunicação (TICS) (SILVA et al., 2006). De acordo com Nelson (1984), o conceito de redes sociais pode ser caracterizado como um conjunto de ligações entre seus atores participantes, sendo essa ligação ocasionada de modo formal e/ou informal, forte ou fraca e também ocorrendo de forma frequente ou esporádica. Castells (1999, p. 498) define as redes sociais como "[...] um conjunto de nós interconectados". Desse modo, há uma relação social entre os atores participantes da rede. 
Dentro da literatura organizacional, o conceito de redes sociais está caracterizado sob três enfoques, sendo que o primeiro busca compreender a formação de redes para uma melhoria dos arranjos organizacionais, o segundo está ligado a processos de cooperação e, por fim, o terceiro enfatiza a compreensão dos relacionamentos organizacionais (ZANCAN; SANTOS; CAMPOS, 2012).

Desse modo, a pesquisa insere-se no segundo enfoque, compreendendo o universo das redes sociais sob a perspectiva de cooperação entre as pequenas e médias empresas inseridas no APL têxtil. Tais empresas buscam aderência ao ambiente de redes sociais para desenvolverem relações entre seus membros e promover a interdependência entre suas atividades. A ideia base do presente artigo caracteriza-se em compreender as relações entre os membros participantes da rede, suas interações e possíveis coordenações para o alcance dos objetivos organizacionais.

\subsection{Conceitos relativos a Arranjos Produtivos Locais (APLs)}

O processo de desenvolvimento regional se contextualiza sob diferentes óticas, levando em consideração as especificidades territoriais (potencialidades locais), com ênfase para as vantagens comparativas ocasionadas pela disponibilidade de força de trabalho e de matéria-prima, com amplo acesso direcionado aos agentes transformadores (WITTMANN; DOTTO; BOFF, 2008).

Originalmente os estudos destinados para as aglomerações empresariais intitularam esse fenômeno como "Distritos Industriais", sendo abordado pelas vertentes econômicas e caracterizado como teoria por meio das contribuições de Marshall (1982).

A princípio, as empresas se concentravam em zonas suburbanas, por motivos de redução de impostos, quando comparados aos impostos cobrados nos grandes centros, o que ocasionou um movimento de migração da população, com suas moradias sendo instaladas ao redor das empresas (MARSHALL, 1982). Posteriormente surge o termo "Sistema de Produção Local" (BRUSCO et al., 1996), direcionado para os distritos da terceira Itália, interpretado como um conjunto de empresas concentradas em uma área específica, com sua produção direcionada para mercados finais de consumo, tendo como exemplos os mercados de vestuário, calçados e de moveleiro.

Atualmente a mudança de nomenclatura levou a substituição do termo "Sistema de Produção local" por "Arranjo Produtivo Local", também compreendido pelo uso da sigla APL. Por meio dessa nova configuração, os APLs podem ser interpretados como esforços estratégicos, com seu foco direcionado para a redução de custos de transações e diminuição da distância espacial entre as empresas participantes do aglomerado, com aspectos de competitividade, interação, cooperação e inovação (KLINK, 2001). Schmitz e Nadvi (1999) descrevem que as aglomerações produtivas são responsáveis por proporcionar o fortalecimento das atividades das empresas, contribuindo para o alcance de uma melhora em suas operações por meio do desenvolvimento de ações conjuntas, as quais podem ser desempenhadas pelas empresas proporcionando uma eficiência coletiva. Nesse caso, os APLs podem proporcionar o desenvolvimento de atividades conjuntas e alavancar as possibilidades empresariais.

Os APLs possuem, como proposta, possibilitar maiores vantagens competitivas, por meio de ações voltadas para a interação e cooperação entre os atores participantes (CASSIOLATO; LASTRES; MACIEL, 2005), geralmente associados à trajetória regional (permeado por uma base cultural, econômica e política dos territórios), também proporcionando o desenvolvimento local e regional, por meio de apoio e articulação com o Estado, além de desenvolvimento tecnológico e formação profissional (WITTMANN; DOTTO; BOFF, 2008). 
Contudo a percepção da necessidade de um agente supraempresa (governança) vem ganhando certa notoriedade ao longo dos anos, sendo fator de destaque para uma perfeita operacionalização dos diversos modelos de APLs, com foco na sua sustentabilidade empresarial e preservação dos diversos interesses dos atores envolvidos (ERBER, 2008). Além disso, o cooperativismo exercido entre as empresas inseridas em um APL pode proporcionar o aumento da competitividade, tendo em vista beneficiar as empresas que se encontram dentro do arranjo, as quais podem ganhar competitividade tendo como base a colaboração entre os atores participantes (AMATO NETO, 2000).

Desse modo, os APLs inseridos em regiões metropolitanas podem ser indutores de desenvolvimento econômico integrado, facilitando o acesso das micros, pequenas e médias empresas no mercado, de acordo com sua estrutura e capacidade de articulação local (SECRETARIA DE DESENVOLVIMENTO ECONÔMICO, CIÊNCIA, TECNOLOGIA E INOVAÇÃO [SDECTI], s.d.). No próximo subitem, será apresentada uma discussão sobre a Região Metropolitana de São Paulo e do APL têxtil foco da presente pesquisa.

\subsection{Região metropolitana de São Paulo e o seu APL têxtil}

O Estado de São Paulo está subdividido em cinco regiões. São elas: Região Metropolitana de Sorocaba, Região Metropolitana de Campinas, Região Metropolitana de São Paulo, Região Metropolitana da Baixada Santista e Região Metropolitana do Vale do Paraíba e Litoral Norte (SÃO PAULO, s.d.).

Para esse estudo será evidenciada a região metropolitana de São Paulo, que comporta em sua configuração um total de 39 municípios e cinco sub-regiões localizadas ao seu entorno territorial, além de contemplar a presença de 43 APLs segundo dados da Secretaria de Desenvolvimento Econômico, Ciência, Tecnologia e Inovação (SDECTI, s.d.). Dentro da perspectiva dos APLs, é necessário compreender que os arranjos podem ser configurados por diversos modelos de empresas, incluindo em sua composição o universo das MPEs. As MPEs possuem um amplo potencial para a geração de emprego, renda e crescimento econômico, também estando vinculadas ao processo de desenvolvimento regional e aspectos de empreendedorismo (QUANDT, 2008).

O APL têxtil localizado na Região Metropolitana de São Paulo surgiu em 2013 por meio de uma iniciativa desenvolvida com o apoio de uma Prefeitura, responsável por coordenar as ações do APL e com a participação des setores organizados da sociedade civil e de grupos empresariais locais. Os apoios destinados ao APL por parte da prefeitura configuram-se entre: qualificação profissional para os colaboradores que trabalham no arranjo, participação dos membros do APL em feiras e eventos de confecções com subsídios do Serviço Brasileiro de Apoio às Micro e Pequenas Empresas (SEBRAE), proposta de redução de Imposto sobre Circulação de Mercadorias e Serviços (ICMS), além de contribuições de Instituições de Ensino Superior (IES) e Ensino Técnico local, atuando com o auxílio de corpo docente para o desenvolvimento de ações e estratégias para o APL têxtil.

Em sua totalidade, o APL conta com 40 empresas têxteis, sendo subdivididas em pequenas e médias empresas, movimentando a economia local, tendo como base a confecção de diversos modelos de vestuário. Os segmentos principais do agrupamento dividem-se nas seguintes modalidades de confecções: trajes a rigor, noivas, roupas profissionais, uniformes escolares, modas de estação e lingerie (roupa íntima). 


\section{METODOLOGIA DE PESQUISA}

O artigo foi conduzido sob a ótica descritiva, caracterizando os atores de uma rede social e suas possíveis interações. A pesquisa descritiva proporciona descrever os fenômenos e fatos de um determinado grupo. Esse tipo de pesquisa possibilita a descrição das características contemporâneas de indivíduos, populações e empresas (GIL, 2010). O objetivo desta pesquisa fica caracterizado em evidenciar as conexões estabelecidas entre os atores do APL têxtil, localizado na Região Metropolitana de São Paulo. Sendo assim, pretendeu-se neste estudo apurar "quais as empresas que fazem negócios dentro da rede" e, posteriormente, qual a "colaboração entre os atores inseridos dentro da rede". Dessa forma, pretende-se evidenciar as empresas que realizam negócios dentro da rede e qual a colaboração exercida entre os atores, sendo que a compreensão dessas informações poderá proporcionar ações de planejamento e desenvolvimento do APL estudado.

Foi utilizado o software UCINET para a interpretação dos dados e posterior compreensão acerca das ligações entre as empresas: "nós da rede". O software UCINET é um programa desenvolvido para Análise de Redes Sociais para fazer análise de grupos, observações dos dados, gráficos e matrizes (ALEJANDRO; NORMAN, 2005).

Análise de Redes Sociais torna-se a metodologia a ser utilizada para a condução desta pesquisa, enquanto o uso do software UCINET configura-se como a ferramenta a ser utilizada. Para complementação do conceito de rede, de acordo com as diretrizes do software UCINET para ARS, a metodologia de pesquisa apresenta alguns indicadores, sendo utilizadas as seguintes medidas: densidade (density) da rede, medida de centralidade, também denominada de Betweennes, responsável por verificar o grau de intermediação da rede, degree, como sendo capaz de identificar o número de contatos diretos que um ator mantém em uma rede, e o closeness, responsável por apresentar a distância de um ator em relação aos outros atores na rede.

A densidade é apresentada na forma de porcentagem, sendo caracterizada como alta e baixa (density). Considerando as relações na forma unidirecional, o cálculo da densidade pode ser efetuado sem o uso do software UCINET por meio da seguinte formulação: LR = [NAT x (NAT - 1)], onde: LR representa a possível quantidade de Ligações da Rede, e a sigla NAT representa o Número de Atores Totais da rede. Depois é necessário calcular a próxima etapa, que consiste na seguinte formulação $D=$ [RE/LR x 100], sendo: RE o número de Relações Empresariais (laços unidirecionais), dividido pelo resultado encontrado em LR, que dessa forma, terá o resultado em formato de porcentagem, e representará a densidade da rede (adaptado de ALEJANDRO; NORMAN, 2005).

O grau de intermediação da rede (Betweenness) justifica-se pela identificação dos atores que fazem a intermediação entre outros atores da rede que funciona como uma espécie de ponte interligando os demais atores participantes da rede (PUCINELLI; GIORDAN, 2015).

A centralidade (Centrality Degree) apresenta-se como o número de atores com os quais cada membro da rede está conectado, denominados como grau de saída (OutDegree) e grau de entrada (InDegree). Sendo que o OutDegree significa os atores da rede que procuram empresas para realizar seus negócios, e o InDegree significa os atores que são procurados para a realização de negócios. A identificação de centralidade pode significar um bom posicionamento em relação aos demais atores da rede, não se tratando de uma posição hierarquicamente fixa, mas pode estar relacionada com aspectos de poder (MARTELETO, 2001). 
A medida (Closeness) justifica-se por verificar as empresas que estão mais próximas umas das outras, apresentando a distância dos atores. Desse modo, quanto maior a proximidade, maior poderá ser o volume de negócios realizados (ALEJANDRO; NORMAN, 2005).

O APL têxtil possui em sua totalidade 40 empresas. Contudo, para esta pesquisa, foram entrevistadas 26 empresas participantes do APL têxtil. Também foram solicitadas as empresas pesquisadas que atribuíssem notas de 0 a 10 (zero discorda totalmente e 10 concorda totalmente) sobre as seguintes perguntas "Meus negócios andam independentes do APL" e "Consigo apoio para novos negócios por meio dos contatos do APL". Dessa forma, a Análise de Redes Sociais torna-se uma abordagem estratégica para estudar os relacionamentos entre grupos/empresas e suas interações.

\section{ANÁLISE E INTERPRETAÇÃO DOS RESULTADOS}

Para a construção das redes foram utilizadas as respostas das seguintes questões:

- Por fazer parte do APL têxtil, a minha empresa fez/faz negócios com a(s) empresa(s) a seguir?

- Por fazer parte do APL têxtil, a minha empresa colabora/ajuda a(s) empresa(s)?

As respostas para a primeira questão permitem a formação da rede de negócios que ocorrem entre as empresas do APL, apresentada na Figura 1. A análise da rede permite uma visão dos negócios que ocorreram ou que ocorrem até o momento da realização da pesquisa.

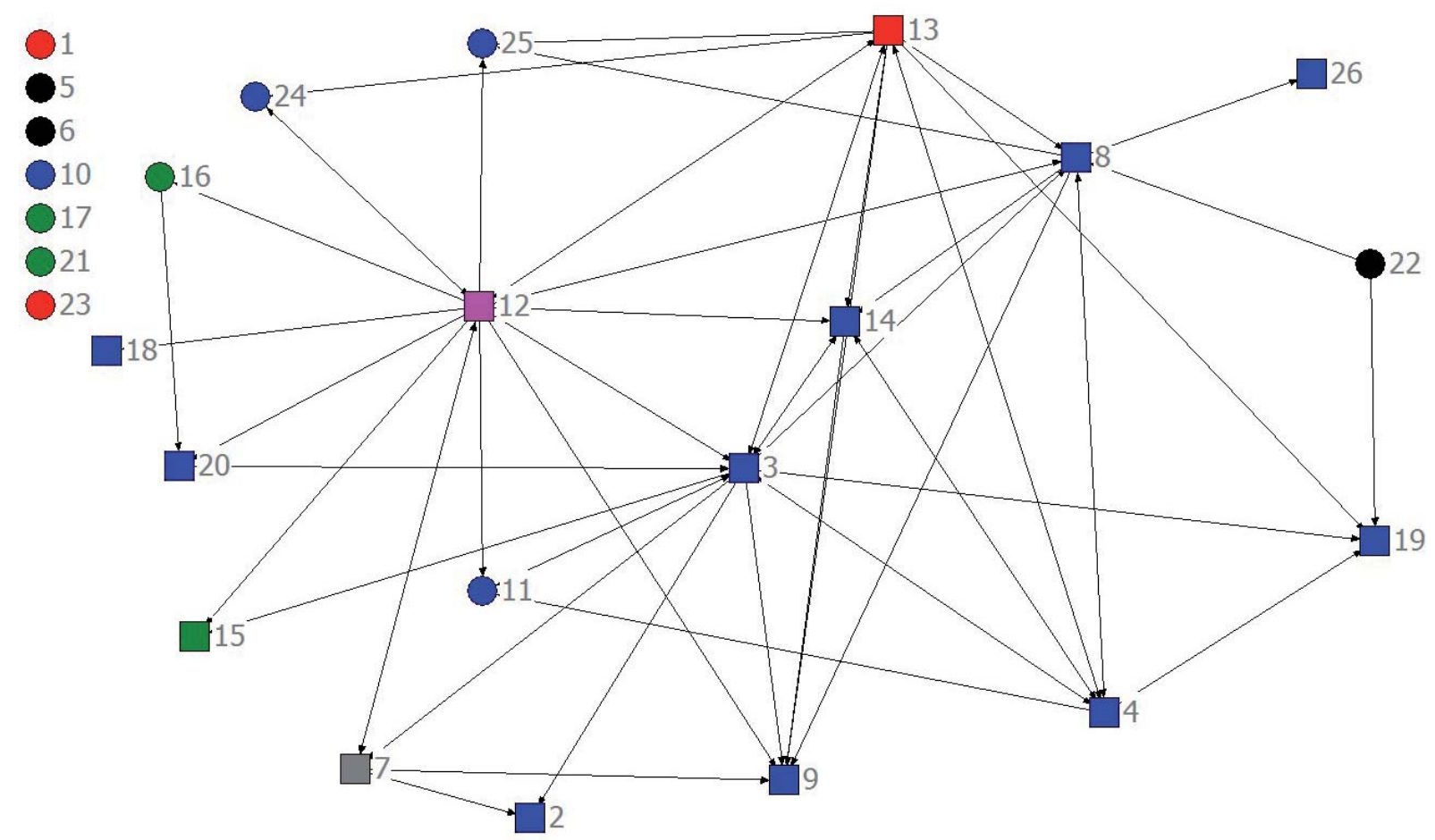

Figura 1 - Modelo de Rede Social - Negócios entre os atores participantes da rede Fonte: Elaborada pelos autores a partir do software UCINET (2016).

Para compreender a Figura 1 da rede, deve-se observar que as empresas representadas por círculos estão inseridas no APL por um período de tempo de um ano. Já as empresas representadas por quadrados estão inseridas no APL há mais de dois anos. 
Nota-se que, das empresas que estão no APL há mais de dois anos (quadrado), todas têm ligações com outras empresas da rede, isto é, fizeram ou fazem negócios entre si, significando que foram desenvolvidas ações conjuntas e, possivelmente, melhorias por meio de cooperações (SCHMITZ; NADVI, 1999). Essa constatação não ocorre para várias empresas que estão inseridas no APL há apenas um ano (círculos). Desse modo, observa-se que o fator tempo torna-se vital para a maturidade dos negócios estabelecidos no APL pesquisado.

Para essa análise, também foi atribuído o uso de cores representando as empresas do APL têxtil, que indicam as notas que as empresas atribuíram para a seguinte pergunta "Meus negócios "andam" independentes do APL" (zero discorda totalmente e 10 concorda totalmente). Desse modo, as cores indicam as notas dadas para as respostas: azul nota 10; vermelho nota 9; preta nota 8; verde nota 7; lilás nota 6; e cinza nota 5. Para este questionamento, não houve nota inferior a cinco atribuída pelas empresas respondentes.

Assim, observam-se os seguintes resultados: quatorze empresas atribuíram nota 10 (azul), representando que seus negócios andam independentemente de estarem constituídas no âmbito do APL. Três empresas atribuíram nota 9 (vermelha), sendo que duas empresas não fazem negócios com outras empresas da rede (não estão conectadas: empresas 1 e 23). Três empresas atribuíram nota 8 (preta), das quais uma está conectada (empresa 22) e duas não estão (empresas 5 e 6). Quatro empresas atribuíram nota 7 (verde), com duas empresas conectadas (empresas 15 e 16) e duas empresas que não fizeram negócios com as outras empresas (empresas 17 e 21). Uma empresa apenas atribui para essa pergunta nota 6 (lilás), sendo representada pela empresa número 12 e também uma única empresa atribui nota 5 (cinza), sendo representada pela empresa número 7. A Figura 2 apresenta, de forma resumida, a quantidade de empresas e suas respectivas notas atribuídas para a questão "Meus negócios andam independentes do APL" (zero discorda totalmente e 10 concorda totalmente).

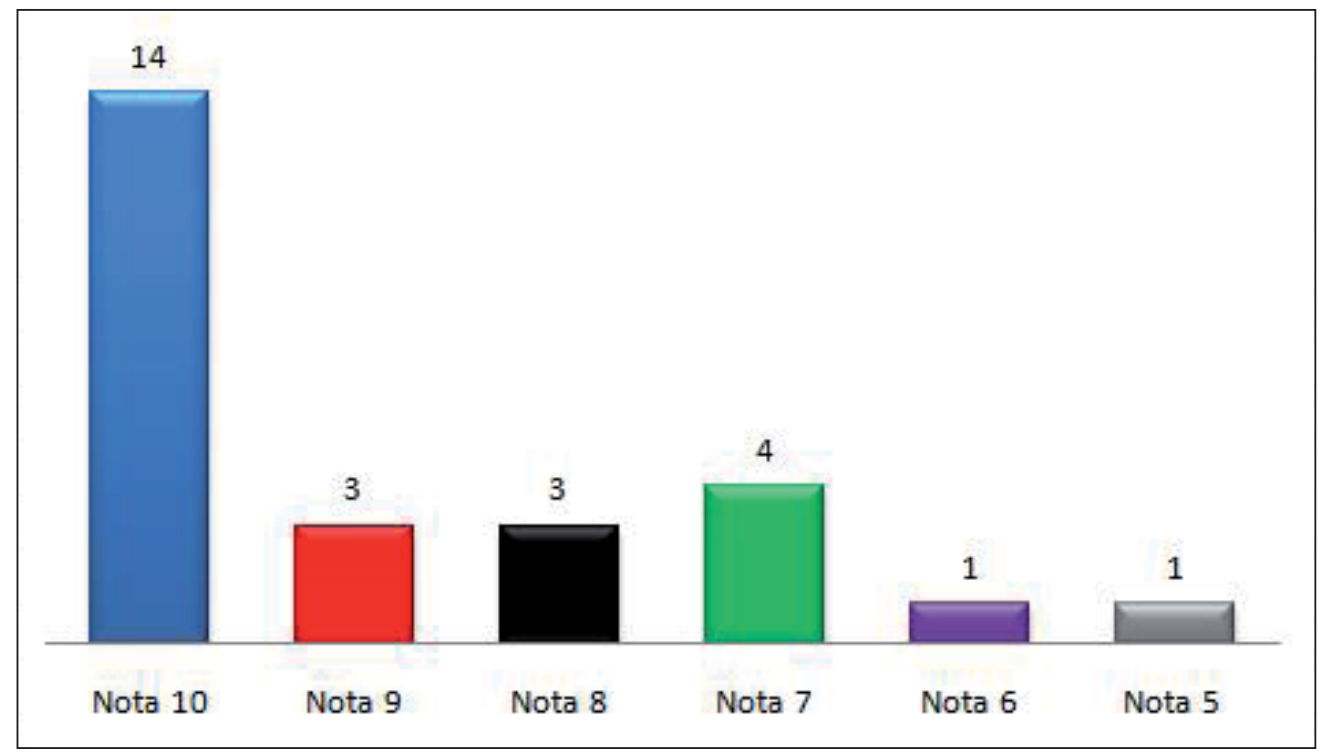

Figura $\mathbf{2}$ - Atribuição de notas segundo os respondentes sobre a questão "Meus negócios andam independentes do APL" Fonte: Elaborado pelos autores (2016). 
A Figura 1 também relaciona os atores que não realizam negócios dentro da rede pesquisada. Nota-se a existência de atores localizados às margens da rede (1, 5, 6, 10, 17, 21 e 23), que são atores que não se relacionam com os demais. Esses atores fazem parte do APL, contudo atuam de forma isolada sem qualquer tipo de relacionamento com os demais em relação a fazer negócios com outras empresas da rede.

Observa-se, por meio dessa análise, que as empresas que fazem parte do APL têxtil, em sua maioria, atribuíram notas que representam independência do APL. Tal informação pode caracterizar a necessidade de uma maior integração das políticas voltadas para o APL, já que o APL têxtil foi uma iniciativa de uma prefeitura local em parceria com um grupo empresarial também inserido na Região Metropolitana de São Paulo.

A visualização da rede e a atribuição das notas podem ser comparadas com as medidas densidade, intermediação e proximidade, resultantes da utilização do software UCINET.

\subsection{Densidade, grau, intermediação e proximidade dos negócios estabelecidos entre os atores da rede}

A densidade da rede leva em consideração o seu número de atores inseridos e o seu número total de possíveis ligações. Na rede analisada, foram detectados 26 atores, o que possibilita 650 possíveis ligações indicando quem fez negócio na rede, seus vínculos ou conexões direcionadas. Por meio do software UCINET, foi constatado que a rede possui em sua configuração 57 vínculos representando os negócios estabelecidos entre os participantes da rede. Poucos negócios foram realizados entre as empresas do APL têxtil. O valor da densidade da rede é 8,76\%, significando que, em geral, as empresas não fazem negócios entre si. Esse valor corrobora o resultado anterior de que há a necessidade de maior integração entre os participantes do APL têxtil.

Com relação à medida de centralidade grau (degree) constata-se que algumas empresas fizeram ou fazem negócios com várias empresas do APL, como por exemplo: a empresa 12 que afirmou ter realizado negócios com outras 13 empresas, está há mais de dois anos no APL e atribuiu nota 6 a respeito da sua independência do APL, relativo aos seus negócios; a empresa 22 está há apenas 1 ano no APL e fez negócios com outras duas empresas, atribuiu nota 8 a respeito de sua independência do APL em termos de negócios realizados. Esses dados também reforçam que deve haver maior interação entre as empresas no APL.

Com relação à medida de centralidade intermediação (betweenness), constata-se que o valor médio percentual é baixo: 1,42\%, isto é, ocorre pouca intermediação de uma empresa na realização de negócios entre outras duas empresas. Uma atuação de intermediadora que tem destaque é a empresa 3, com relação à independência dos negócios, que conferiu nota 9 a si mesma, sendo que está há mais de dois anos no APL e fez negócios com outras 11 empresas, apresentando um valor de intermediação de 67,67 (11,28\% da rede), porém pode-se dizer que é uma das exceções, pois a maioria não fez o papel de intermediadora. A medida de centralidade proximidade (closeness) também apresentou pequeno valor (média de 6,86). Fica constatado que o APL precisa incentivar um maior contato entre as empresas.

De acordo com a segunda questão da pesquisa, na Figura 3 é apresentado o modelo da rede com base na colaboração/ajuda entre os atores participantes do APL têxtil. 


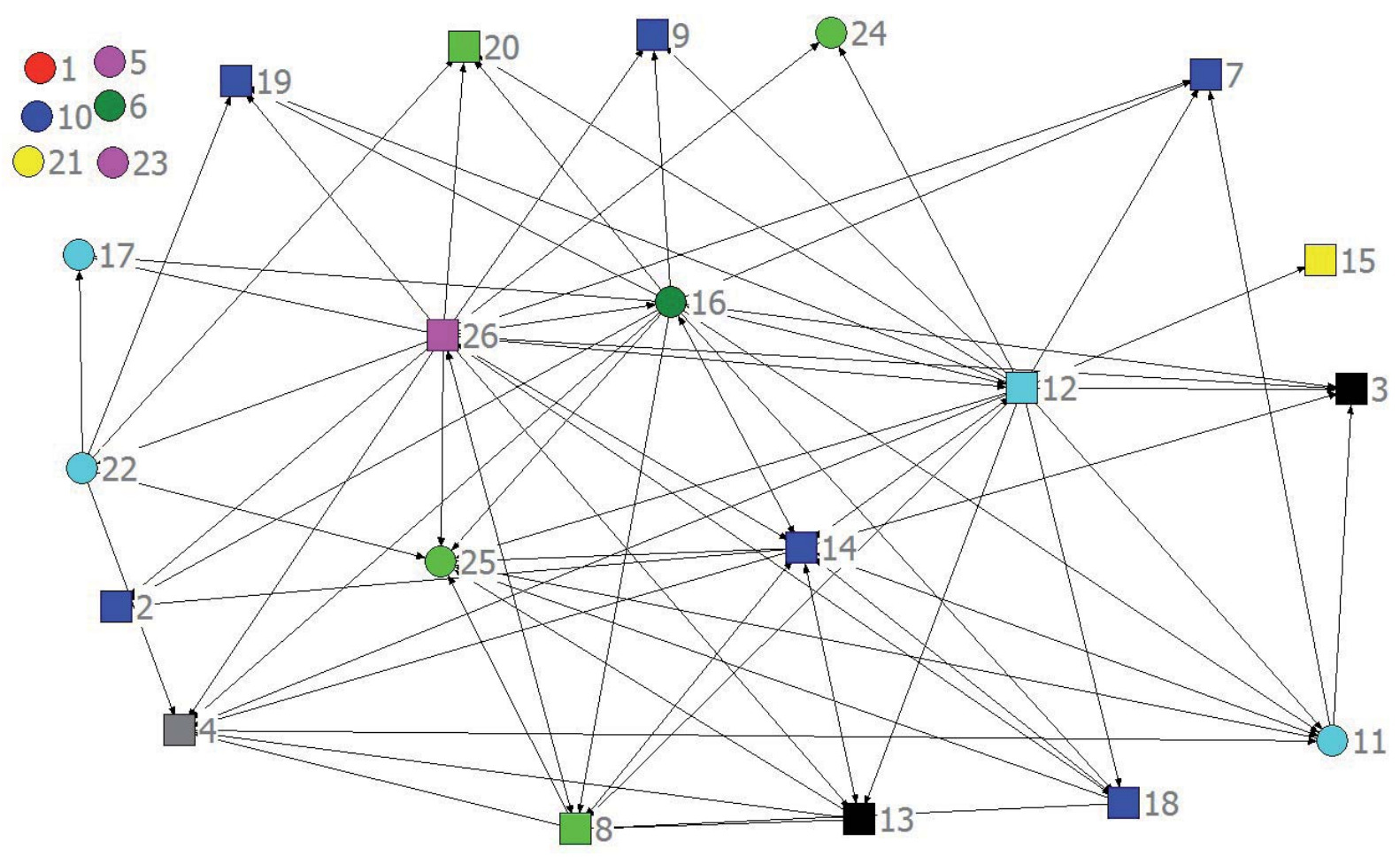

Figura 3 - Modelo de Rede Social - Ajuda/colaboração entre as empresas da rede Fonte: Elaborada pelos autores a partir do software UCINET (2016).

Pode-se observar, de acordo com a Figura 3, as empresas inseridas na análise de redes sociais por meio de suas "ligações entre os atores", assim como também são observados os atores sem ligações com os demais, representados pelos números $1,5,6,10,21$, e 23, isto é, com nítida ausência de ajuda.

As empresas participantes do APL têxtil também foram questionadas acerca de "Conseguirem apoio para novos negócios por meio dos contatos do APL". Sendo que, as cores da Figura 4 representam as notas obtidas entre as empresas pesquisadas (zero discorda totalmente e 10 concorda totalmente). As cores/notas estão representadas sob a seguinte forma: verde claro nota 10; verde escuro nota 9; azul claro nota 8; cinza nota 7; amarelo nota 6; azul nota 5; vermelho nota 4 ; lilás nota 1 e preta nota 0.

Por meio das respostas obtidas frente às empresas pesquisadas, seguem os dados referentes às notas atribuídas. Quatro empresas atribuíram nota 10 (verde claro), representada pelas empresas 8, 20, 24 e 25. Duas empresas atribuíram nota 9 (verde escuro), representada pela empresa 6 (sem ligações na rede) e pela empresa 16 (com ligações na rede). Quatro empresas atribuíram nota 8 (azul claro), estando representadas pelas empresas 11, 12, 17 e 22. Uma única empresa atribui nota 7 (cinza), representada pela empresa número 4. Duas empresas atribuíram nota 6 (amarelo), sendo caracterizadas pelas empresas 15 (sem ligação) e 21 (participante da rede). Sete empresas atribuíram para essa pergunta nota 5 (azul), representadas pelas empresas 2, 7, 9, 14, 18 e 19 (inseridas na rede) e empresas 10 (sem ligações na rede). Uma única empresa atribuiu nota 4 (vermelha), representada pela empresa número 1 (sem ligações na rede). Três empresas atribuíram nota 1 (lilás), caracterizadas pelas empresas 5 e 23 (sem ligações na rede) e empresa 26 (participante da rede). Duas empresas atribuíram nota zero (preta), empresas 3 e 13 (ambas as empresas participantes da rede). A Figura 4 apresenta de forma resumida a quantidade de 
empresas e suas respectivas notas atribuídas para a segunda questão "Conseguirem apoio para novos negócios por meio dos contatos do APL".

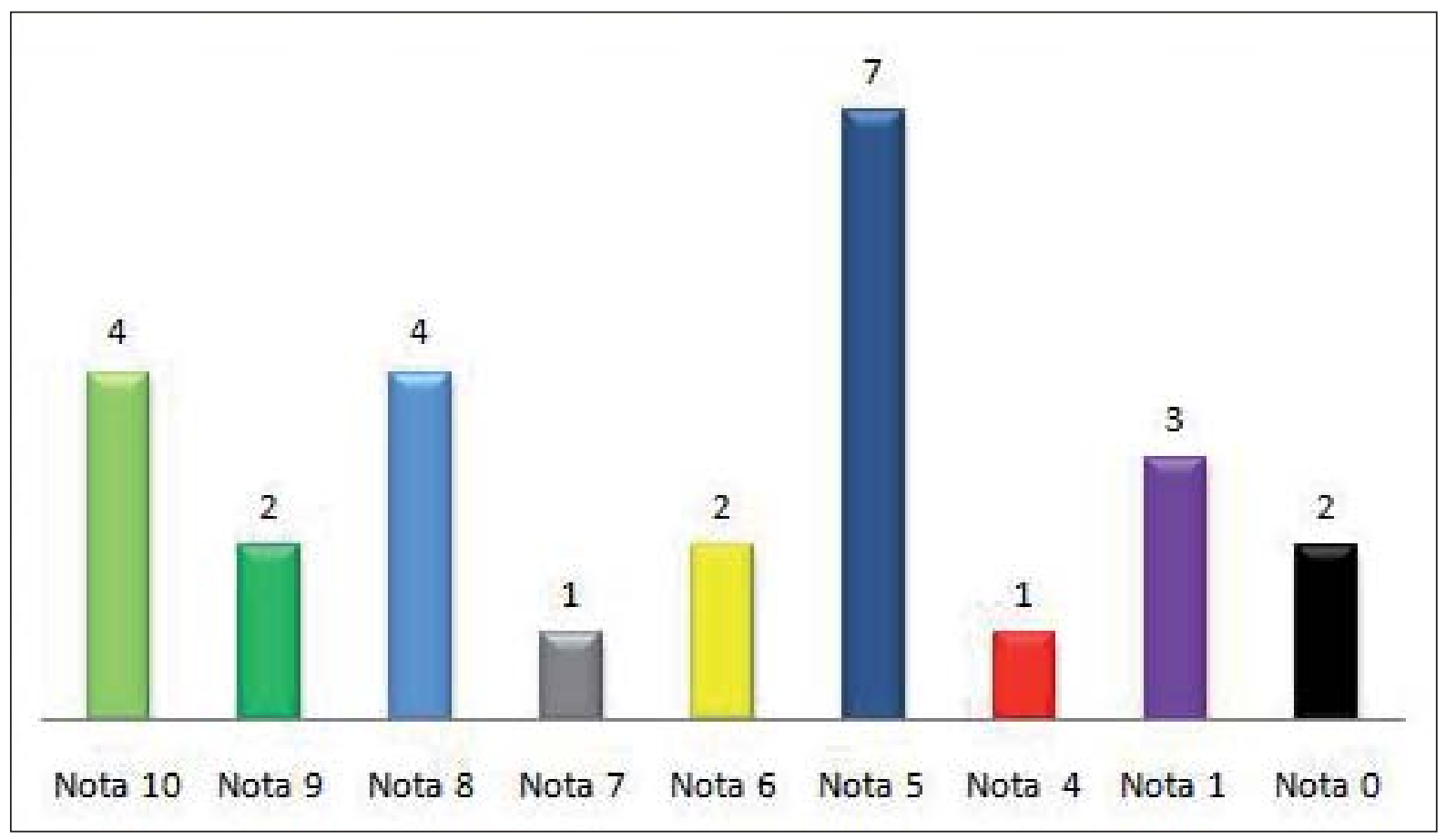

Figura 4 - Atribuição de notas segundo os respondentes sobre a questão "Conseguirem apoio para novos negócios por meio dos contatos do APL"

Fonte: Elaborado pelos autores (2016).

Nota-se que, por meio dessa análise, treze empresas atribuíram notas entre 6 e 10, demonstrando a importância do APL para conseguir apoio para novos negócios e novos contatos. Sete empresas atribuíram nota 5, demonstrando certa imparcialidade referente à obtenção de novos negócios e novos contatos por meio do APL, e seis empresas atribuíram notas entre 4 e 0 , caracterizando um baixo estímulo para obtenção de novos negócios por meio do APL têxtil.

De acordo com tais notas atribuídas, pode-se evidenciar que o APL têxtil possui certa importância quando relacionado com a possibilidade de apoio para atrair novos negócios e novos contatos para as empresas participantes, pois até mesmo empresas sem vínculos com a rede conseguiram novos negócios e contatos, tendo como base as notas atribuídas durante a pesquisa.

\subsection{Densidade, grau, intermediação e proximidade das colaborações realizadas na rede}

Por meio do software UCINET foi constatado que a rede possui em sua configuração 79 "ligações", sendo as relações entre os atores participantes a respeito da colaboração/ajuda entre elas. Dessa forma, o valor da densidade da rede é de 12,15\%, valor baixo para a ajuda/ colaboração dentro do APL.

Com relação à medida de centralidade grau (degree) constata-se que algumas empresas colaboram/ajudam várias empresas do APL, como por exemplo: a empresa 26, que afirmou ter colaborado/ajudado outras 17 empresas, está há mais de dois anos no APL e atribuiu nota 1 , isto é, não conseguiu apoio para novos negócios por meio dos contatos do APL. A empresa 16 está há apenas 1 ano no APL e colaborou/ajudou 14 empresas e atribuiu nota 9 a respeito 
de conseguir apoio para novos negócios. Os resultados indicam que há uma distribuição maior nas notas e a colaboração/ajuda ainda é pequena dentro do APL. Dessa forma, constata-se que devem ser feitos esforços para maior interação entre as empresas.

Sobre a medida de centralidade intermediação (betweenness), constata-se que o valor médio percentual é baixo, 1,18\%, isto é, ocorre pouca intermediação de uma empresa na colaboração/ajuda entre outras duas empresas. Uma atuação de intermediadora que tem destaque é a empresa 14 (com relação a conseguir novos negócios por meio dos contatos do APL conferiu nota 5 a si mesma, está há mais de dois anos no APL e colaborou/ajudou 11 empresas), que apresentou um valor de intermediação de 69,88 (11,65\% da rede). O baixo valor de intermediação da rede indica que as empresas precisam colaborar/ajudar mais as outras empresas. A medida de centralidade proximidade (closeness) também apresentou pequeno valor (média de 7,36). Fica constatado que o APL precisa incentivar mais a colaboração e a ajuda entre as empresas.

Com base na densidade das redes, nas medidas de centralidade e nas notas atribuídas, constata-se que o APL, até o momento, pouco contribuiu para o desenvolvimento das empresas, e esse fato não coaduna com a afirmação dos autores Schmitz e Nadvi (1999). No estágio atual, não se constatou que fazer parte do APL proporcione o fortalecimento das atividades das empresas e que contribua para o alcance de uma melhora nas suas operações (SCMITZ, NADVI, 1999).

Segundo Cassiolato, Lastres e Maciel (2005), a proposta dos APLs é possibilitar maiores vantagens competitivas, por meio da interação e cooperação entre as empresas, porém, no APL têxtil estudado, essas ações parecem tímidas e devem ser avaliadas e incentivadas para o desenvolvimento do APL e das empresas.

\section{CONSIDERAÇÕES FINAIS}

Os APLs surgiram como fatores de diferenciação, sendo respaldados pelas aglomerações empresariais, as quais proporcionavam vantagens competitivas, inovações empresariais, interação e aspectos de alavancagem empresarial por meio da cooperação entre os atores. Os APLs podem proporcionar uma melhora no desempenho das atividades empresariais, dessa forma, estabelecendo ações conjuntas que geram o fortalecimento das atividades das empresas por meio de cooperações que podem resultar em benefícios mútuos para as empresas inseridas nos arranjos produtivos locais.

De acordo com a primeira pergunta: Por fazer parte do APL têxtil, a minha empresa fez/ faz negócios com a(s) empresa(s) a seguir? Obteve-se como resultados que a densidade da rede é baixa, o mesmo ocorrendo com as demais medidas de centralidade (density, betweenness e closeness) e as notas atribuídas.

O mesmo ocorre com os resultados relativos à segunda pergunta: por fazer parte do APL têxtil, a minha empresa colabora/ajuda a(s) empresa(s)? As medidas foram inexpressivas na avaliação da colaboração entre as empresas.

Conclui-se, por meio da presente pesquisa, que poucos negócios foram feitos com base nas medidas analisadas e, dessa forma, o APL têxtil localizado na Região Metropolitana de São Paulo precisa trabalhar mais em conjunto, ou então cabe verificar a ocorrência de outros fatores que estejam impactando na atuação do APL, para dessa forma proporcionar uma maior alavancagem dos negócios e da colaboração entre as empresas inseridas. Contudo o APL têxtil torna-se viável referente à atração de novos negócios e novos contatos e, com novos estímulos, os novos negócios e novos contatos podem se realizar. 
A reflexão que deve ser feita também deve levar em conta os agentes externos, tais como prefeituras, o SEBRAE e outros, de forma a levar em conta as potencialidades locais, a disponibilidade de força de trabalho e de matéria-prima, contatos com as instituições de ensino, enfim, com agentes transformadores conforme afirmam Wittimann, Dotto e Boff (2008).

A ARS ajuda a compreender as ações realizadas e respectivamente as ações não realizadas pelos atores inseridos na rede, podendo obter uma visualização das interações exercidas entre as empresas. Quanto aos aspectos de grau de centralidade, intermediação e aproximação da rede estudada, os valores foram inferiores, indicando o baixo volume de negócios estabelecidos entre as empresas.

Como limitação desta pesquisa, tornou-se evidente a falta de contato com algumas empresas situadas no APL têxtil, desse modo, não contribuindo para uma melhor compreensão das ações desenvolvidas pelo APL e sobre os questionamentos acerca dos negócios realizados entre os atores da rede e suas colaborações. Como sugestão para futuras pesquisas, o estudo pode ser replicado a fim de compreender se houve melhoras e avanços significativos quanto aos negócios realizados entre os atores da rede e suas colaborações. Também cabe observar se houve a entrada e/ou saída de empresas do APL têxtil, além de tentar contatar um maior volume de empresas a serem pesquisadas tendo como base o número de empresas participantes do APL.

Nota-se que a análise de redes sociais está relacionada a diversas áreas do conhecimento, com nítidas vantagens para compreensões acerca da formação de redes sociais. Por meio da pesquisa realizada, a análise de redes sociais fica caracterizada por revelar informações importantes relacionadas aos contextos empresariais como nível de densidade da rede, número de ligações da rede, grau de intermediação e de aproximação. Tais informações podem proporcionar para as empresas o desenvolvimento de estratégias para minimizar problemas, prospectar novos contatos dentro da própria rede, e alavancar suas ações relacionadas ao processo de interação com as demais empresas inseridas na rede, além de auferir ações de melhorias internas, ligadas ao contexto da própria rede.

\section{REFERÊNCIAS}

AHUJA, Gautam. Collaboration networks, structural holes, and innovation: a longitudinal study. Administrative Science Quarterly, v. 45, n. 3, p. 425-55, set. 2000.

ALEJANDRO, Velázquez Álvarez; NORMAN, Aguilar Gallegos. Manual introdutório à análise de redes sociais. Medidas de centralidade. Jun. 2005. Disponível em: <http://www2.unicentro.br/Imqqa/files/2016/05/ Manualintrodutorio_ex_ucinet.pdf>. Acesso em: 3 maio 2016.

AMATO NETO, João. Redes de cooperação produtiva e clusters regionais: oportunidades para as pequenas e médias empresas. São Paulo: Atlas, 2000.

BRUSCO, Sebastiano; CAINELLI, Giulio; FORNI, Fabrizia; FRANCHI, Maura; MALUSARDI, Alberto; RIGHETTI, Roberto. The evolution of industrial districts in Emilia-Romagna. Geneva: ILO/IILS, 1996.

CARDOSO, Univaldo Coelho; CARNEIRO, Vânia Lúcia Nogueira; RODRIGUES, Édna Rabêlo Quirino. APL: arranjo produtivo local. Brasília: SEBRAE, 2014.

CASSIOLATO, José E.; LASTRES, Helena; MACIEL, Maria Lucia Maciel. Systems of innovation and development: evidence from Brazil. Cheltenham: Edward Elgar, 2005.

CASTELLS, Manuel. A sociedade em rede. São Paulo: Paz e Terra, 1999.

ERBER, Fabio Etefano. Eficiência coletiva em Arranjos Produtivos Locais Industriais: comentando o conceito. Nova Economia, Belo Horizonte, MG, v. 18, n. 1, p. 11-32, jan./abr. 2008. 
FARINA, Milton Carlos. Análise de redes sociais. In: GOULART, Elias Estevão (Org.). Mídias sociais: uma contribuição de análise. Porto Alegre, RS: EDIPUCRS, 2014.

GIL, Antonio Carlos. Como elaborar projetos de pesquisa. 5. ed. São Paulo: Atlas, 2010.

KLINK, Jeroen Johannes. A cidade região: regionalismo e reestruturação no Grande ABC Paulista. Rio de Janeiro: DP\&A, 2001.

MARSHALL, Alfred. Princípios de economia. São Paulo: Abril Cultural, 1982.

MARTELETO, Regina Maria. Análise de redes sociais - aplicação nos estudos de transferência da informação. Revista Ciência da Informação, Brasília, v. 30, n. 1, p. 71-81, jan./abr. 2001.

NELSON, Reed. O uso da Análise de Redes Social no estudo das estruturas organizacionais. Revista de Administração de Empresas, São Paulo, v. 24, n. 4, p. 150-7, out./dez. 1984.

PUCINELLI, Ricardo Henrique; GIORDAN, Marcelo. Análise sociométrica de interações entre professores de ciências em um programa on-line de formação continuada. In: ENCONTRO NACIONAL DE PESQUISA EM EDUCAÇÃO EM CIÊNCIAS (ENPEC), 10., 24 a 27 de novembro de 2015. Anais... Águas de Lindóia, SP, 2015. p. 1-8.

QUANDT, Carlos Olavo. O desafio da inovação em pequenas e médias empresas: análise de redes interorganizacionais no Arranjo Produtivo Local de Imbituva, Paraná. In: SIMPÓSIO DE GESTÃO DA INOVAÇÃO TECNOLÓGICA, 25. Anais... Brasília, out. 2008. p. 1-16.

SECRETARIA DE DESENVOLVIMENTO ECONÔMICO, CIÊNCIA, TECNOLOGIA E INOVAÇÃO (SDECTI). Arranjos Produtivos Locais (APLs). [s.d.]. Disponível em: <http://www.desenvolvimento.sp.gov.br/arranjosprodutivos-locais-(apls)>.. Acesso em: 1으. 2017.

SÃO PAULO (Estado). Subsecretaria de Assuntos Metropolitanos. [s.d.]. Disponível em: <http://www. sdmetropolitano.sp.gov.br/portalsdm/unidades-regionais.jsp>. Acesso em: 19 jul. 2016.

SCHMITZ, Hubert; NADVI, Khalid. Clustering and industrialization: introduction. World Development, v. 27, n. 9, p. 1503-14, set. 1999.

SCOTT, John. Social network analysis: a handbook. 2. ed. London: SAGE Publications Ltd, 2000.

SILVA, Antônio Brás de Oliveira; MATHEUS, Renato Fabiano; PARREIRAS, Fernando Silva; PARREIRAS, Tatiane A. Silva. Estudo da rede de co-autoria e da interdisciplinaridade na produção científica com base nos métodos de análise de redes sociais: avaliação do caso do programa de pós-graduação em ciência da informação - PPGCI/UFMG. Encontros Bibli: Revista Eletrônica Biblioteconomia e Ciência da Informação, Florianópolis, número especial, p. 179-94, 1o sem. 2006.

TOMAÉL, Maria Inês; MARTELETO, Regina Maria. Redes sociais: posições dos atores no fluxo da informação. Encontros Bibli: Revista Eletrônica de Biblioteconomia e Ciência da Informação, Florianópolis, SC, número especial, p. 75-91, 10 sem. 2006.

WASSERMAN, Stanley; FAUST, Katherine. Social network analysis: methods and applications. Cambridge: Cambridge University Press, 1994.

WITTMANN, Milton Luiz; DOTTO, Dalva Maria Righi. Arranjo Produtivo Local -APL. In: SIEDENBERG, Dieter Rugard. Dicionário do desenvolvimento regional. Santa Cruz do Sul, RS: Edunisc, 2006.

WITTMANN, Milton Luiz; DOTTO, Dalva Maria Righi; BOFF, Vilmar Antonio. Desenvolvimento regional: análise de processos organizacionais de desenvolvimento integrado. In: BECKER, D.; WITTMANN, M. (Org.). Desenvolvimento regional: abordagens interdisciplinares. Santa Cruz do Sul, RS: Edunisc, 2008.

ZANCAN, Claudio; SANTOS, Paulo da Cruz Freire; CAMPOS, Vanessa Oliveira. As contribuições teóricas da análise de redes sociais (ARS) aos estudos organizacionais. Revista Alcance, Biguaçu, SC, v. 19, n. 1, p. 62-82, jan./mar. 2012. 


\section{Sobre os autores:}

Esdras da Silva Costa: Doutorando em Administração pela Universidade Municipal de São Caetano do SUL (USCS). E-mail: esdras-dasilva@bol.com.br

Alessandra Preto Bitante: Doutora em Administração pela Universidade Municipal de São Caetano do Sul (USCS). E-mail: alessandra.bitante@gmail.com

Lidiane Campos Britto: Doutoranda em Administração pela Universidade Municipal de São Caetano do Sul (USCS). E-mail: lidiane_britto@yahoo.com.br

Luciane Ribeiro Dias Pinheiro: Doutoranda em Administração pela Universidade Municipal de São Caetano do Sul (USCS). E-mail: dias.luciane@ig.com.br

Milton Carlos Farina: Doutor em Administração, Professor titular do curso de Mestrado e Doutorado da Universidade Municipal de São Caetano do Sul (USCS). E-mail: milton.farina@uscs.edu.br 
